\title{
Differential Diagnosis of the Dementias of Unknown Origin: A Clinician's View
}

\author{
V.A. Kral
}

\begin{abstract}
The close cooperation of clinical and laboratory research has helped to clarify the etiology of some of the dementing processes of the senium. However, the necessary investigations are complicated, laborious, expensive and can be carried out only in well equipped centres in larger cities. This restricts the number of patients who eventually may benefit from these investigations to a small number. What is needed for the psychogeriatric practice particularly in rural areas and smaller cities are simple diagnostic guidelines for the psychiatrist to answer the question whether the patient suffers from a dementia and if so whether the dementia is in all probability due to a primary degenerative process of the brain parenchyma or of the cerebral vasculature or is it due to another cause.

If degeneration of the brain parenchyma seems the prevalent pathogenetic mechanism one would like to establish in a given case which of the known degenerative processes is most probably present in order to avoid mistakes in clinical judgement with their often life threatening consequences.
\end{abstract}

RÉSUMÉ: Le diagnostic différentiel des démences d'étiologie inconnue: le point de vue d'un clinicien. Une collaboration étroite entre les équipes de recherche clinique et les équipes de recherche en laboratoire a aidé à classifier l'étiologie de quelques-uns des processus démentiels de la vieillesse. Cependant, les investigations requises sont compliquées que dans des centres bien équipés, situés dans des grandes villes. Pour toutes ces raisons, ce n'est qu'un petit nombre de patients qui peut éventuellement bénéficier de ces investigations. Ce dont a besoin le praticien en psychogériatrie exerçant en milieu rural ou dans les petites villes, ce sont des schémas diagnostiques lui permettant de répondre à la question suivante: le patient souffre-t-il de démence? Si oui, cette démence est-elle, selon toute probabilité, due à un processus dégénératif primaire au niveau du parenchyme cérébral ou du système vasculaire cérébral, ou est-elle due à une autre cause?

Si la dégénérescence du parenchyme cérébral semble être le mécanisme pathogénique prédominant, il est souhaitable de chercher à établir dans chaque cas particulier, lequel des processus dégénératifs connus est probablement en cause, afin d'éviter des erreurs de jugement clinique qui peuvent souvent avoir des conséquences fatales.

Can. J. Neurol. Sci. 1986; 13:381-382

Many of the speakers at this symposium are here in a twofold capacity: as researchers who try to clarify the etiology, pathology and pathophysiology of the dementing processes, and to understand how the brain pathology translates into the cognitive and personality changes which we call dementia, and at the same time, we also treat the patients suffering from the various forms of dementia. This presentation is a clinical one. It is presented to remind all of us that as physicians we treat not the diseases we are researching, but individual patients. This does not mean that we should disregard the results of our research, but we should apply only those recommendations which are appropriate for the individual patient and disregard those which are not. On the other hand, we should apply recommendations coming from research in other disease entities when they appear appropriate.

As it is impossible to cover the whole area of differential diagnosis as indicated in the title of this paper within the time limit of ten minutes, I have to restrict myself to three specific areas. These include the acute confusional states, the normotensive hydrocephalus and depressive pseudodementias. These are areas where neglect of the results of research or inaccurate observation frequently lead to mistakes and harm to the patients and that is what motivated this paper.

The acute confusional states of the aged were introduced as a nosological entity by $\mathbf{M}$. Roth ${ }^{1}$ and they turned out to be of great practical importance. Many of them clear up spontaneously within a short time and psychiatrists do not become involved. Some of these, on the other hand, end fatally. In between is a great number of cases of moderate to great severity, part of which clear up while another part change gradually into a picture indistinguishable from Alzheimer's Disease, both clinically and pathologically.

The mistakes which I observed being made were that a number of patients were diagnosed very shortly after the onset of the confusional state as suffering from Alzheimer's Disease and were institutionalized in mental hospitals and/or other 
institutions. Some of these patients were not discharged even after the confusional state had cleared up. This caused unnecessary suffering to the patient as well as to his family. Such mistakes can be avoided if one keeps in mind two essential criteria for the acute confusional state, namely the sudden onset in temporal connection with an acute stress whether physical or mental, and secondly, that in contrast to Alzheimer's Disease, personal orientation remains intact for a long time, actually through the whole duration of the confusional state. ${ }^{2}$ The CT Scan is not decisive in an old person.

The second area of concern is the normotensive hydrocephalus and the treatment of it - the shunt. When this entity was established, a diagnostic triad was reported as clinically characteristic for it: urinary incontinency, ataxic gait and progressive memory loss. The CT Scan shows dilation of the ventricles and moderate cortical atrophy. Certain more specific criteria have been since described by Katzman and others. The syndrome is reported as being alleviated, even cured in some cases by a cerebral shunt when applied in time.

What made me concerned was the erroneous introduction of the shunt which proved harmful to the patient. It is clear that the above mentioned triad can be gone through in different dementing processes that do not require establishment of a shunt like Alzheimer's or Pick's or Creutzfeldt-Jakob's disease. However, a shunt would ordinarily not harm such a patient, although any kind of surgical procedure brings with it a certain operative risk. I observed a purulent meningitis in one case, and the development of a status epilepticus in another, the latter in close temporal connection with the surgery.

More serious are the cases where a shunt is established on the basis of inadequate knowledge and sloppy clinical examination, as the following case shows: An 83 year old man became deeply depressed. It was his third endogenous depression. He was admitted to hospital. The first night he got a sleeping pill which the nurse was to repeat p.r.n. She did. The patient slept deeply but during the night he was incontinent of urine, the first time in his life as his wife of more than 30 years stated. On examination next morning the deeply depressed patient who fought the wish to end it all and his religious conviction that suicide was a sin answered orientation questions irrelevantly and was considered demented. The gait was not ataxic but showed the type seen in some old people where it is difficult to decide whether they suffer from apraxia of walking or an anxiety produced abasia. The patient had a shunt because he was assumed to have the characteristic trait and the CT Scan showed some dilation of the lateral ventricle.

The patient did not improve but developed a stress induced acute confusional state as described above. Another CT Scan showed fluid over both parieto-temporal regions. Two more shunts were placed in the patient's head and after about two weeks he was discharged with three shunts into a chronic hospital in a provincial city. It is not known whether he ever recovered from his confusion.

On the other hand, a shunt when appropriately applied by a clinician with sound judgement for the patient even when not considered usual by others can be of great help. As the following case shows: A man in his sixties was first considered a normal tension hydrocephalus. However, the CT Scan showed a space occupying lesion in the posterior fossa near the foramen magnum. The surgeon decided against the advice of others against removing the tumor and introduced a shunt. During an observation period of two years, there is hardly a change in the tumor size and the patient is functioning well.

The third area I intend to mention is the depressive pseudodementias of the aged. ${ }^{3}$ Here the same error frequently prevails as the acute confusional states, namely that the cognitive deficit is considered the main feature while the depression is considered of minor importance. The patient is then sent to a chronic institution where he or she may spend years even when recovered from the depression.

I have mentioned only three of the areas of clinical concern. I hope that future research will enable us to find more precise criteria to apply properly to the appropriate patients.

\section{REFERENCES}

1. Roth M. The natural history of mental disorder in old age. J Ment Sci 1955; 101: 281-301.

2. Kral VA. Stress Reactions in Old Age (Pres at Symp on Gerontol Nov. 1966) Laval Medical 1967; 38: 561-566.

3. Kral VA. The Relationship Between Senile Dementia (Alzheimer Type) and Depression. Can J Psychiatry 1983; 28: 304-306. 